\title{
Malignant phyllodes tumor in a patient with hereditary retinoblastoma: a case report and literature review
}

\author{
Damon D. Shearer, DO, ${ }^{1}$ Ryan W. Askeland,MD, ${ }^{2}$ Jeong Mi Park, MD, PhD, ${ }^{1}$ \\ Laurie L. Fajardo, MD, MBA, ${ }^{1}$ Limin Yang, MD, PhD ${ }^{1}$
}

Key Words: retinoblastoma, phyllodes, leiomyosarcoma, breast neoplasms

\begin{abstract}
Patients with hereditary retinoblastoma are at increased risk for second malignancies, most notably sarcomas, particularly after treatment with radiation. Malignant phyllodes tumor is a rare secondary malignancy in these patients. We present a review of the literature and report of a patient with hereditary retinoblastoma who developed two secondary malignancies, including malignant phyllodes tumor. The patient's phyllodes tumor presented as a palpable breast mass with suspicious findings on mammogram and ultrasound. The mass was shown to be at least a borderline phyllodes tumor via sonographic percutaneous biopsy and confirmed malignant phyllodes tumor on final surgical excision.

${ }^{1}$ Department of Radiology, University of lowa Hospitals and Clinics, lowa City, lowa ${ }^{2}$ Department of Pathology, University of lowa Hospitals and Clinics, lowa City, lowa
\end{abstract}

Introduction

In the United States, only 250-300 cases of retinoblastoma are diagnosed each year. ${ }^{1}$ Patients with hereditary retinoblastoma, representing approximately $40 \%$ of patients, have germline mutations in the retinoblastoma gene, $R B 1$, and frequently have bilateral or multifocal unilateral tumors. ${ }^{2}$ Due to improvements in diagnosis and treatment, patients with hereditary retinoblastoma are living into adulthood, and secondary malignancies are now the most common cause of death. ${ }^{3-7}$ Radiation therapy for hereditary retinoblastoma has been identified as a causative factor in the development of subsequent malignancies. ${ }^{3,5,7}$ The most common secondary malignancies reported include sarcoma, carcinoma, intracranial primitive neuroectodermal tumor, and melanoma. ${ }^{5}$ Breast, lung, and bladder carcinomas have been identified as the most frequent

Please cite this paper as: Shearer DD, Askeland RW, Park JM, Fajardo LL, Yang L. Malignant phyllodes tumor in a patient with hereditary retinoblastoma: a case report and literature review. Proc Obstet Gynecol. 2013;3(2):Article 5 [9 p.]. Available from: http://ir.uiowa.edu/pog/. Free full text article.

Corresponding author: Limin Yang, MD., Ph.D., Department of Radiology, University of lowa Hospitals and Clinics, 200 Hawkins Dr., lowa City, lowa 52242 Tel: (319) 353-6339 Fax: (319) 356-2220 e-mail: liminyang@uiowa.edu

This is an Open Access article distributed under the terms of the Creative Commons Attribution 3.0 Unported License (http://creativecommons.org/licenses/by/3.0), which permits unrestricted use, distribution, and reproduction in any medium, provided the original work is properly cited. 
secondary epithelial malignancies. ${ }^{6}$

Phyllodes tumors of the breast are uncommon, representing less than $1 \%$ of breast tumors. ${ }^{8}$ They usually occur in women $40-50$ years of age and often present as palpable masses. Phyllodes tumors are commonly classified as benign, borderline or malignant, with approximately $10-20 \%$ of tumors classified as malignant. ${ }^{8}$ The average annual age-adjusted incidence rate of malignant phyllodes is 2.1 per 1 million women. ${ }^{9}$ The database of the National Cancer Institute's Surveillance, Epidemiology, and End Results (SEER) Program documented only 158 patients with malignant phyllodes from 1973-1981. ${ }^{10}$ Phyllodes tumors have been described with alterations in the expression of the retinoblastoma protein. ${ }^{11}$

The occurrence of phyllodes tumor of the breast in the setting of retinoblastoma has only been reported in two patients. ${ }^{12}$ We report a case of malignant phyllodes tumor of the breast occurring in a patient with a history of hereditary retinoblastoma as an infant and leiomyosarcoma of the nasal cavity as a young adult. The imaging findings of phyllodes tumors and the association between these neoplasms are reviewed.

\section{Case Report}

The patient was diagnosed with hereditary bilateral retinoblastoma and treated with radiation therapy at four months of age. She then developed a leiomyosarcoma of the nasal cavity at age 29 (Figs. 1 \& 2), which was diagnosed on excisional biopsy. She subsequently had a recurrence of the leiomyosarcoma treated with surgery at 30 years of age. The patient was never treated with chemotherapy and no radiation therapy was given for her nasal leiomyosarcoma before diagnosis of phyllodes.

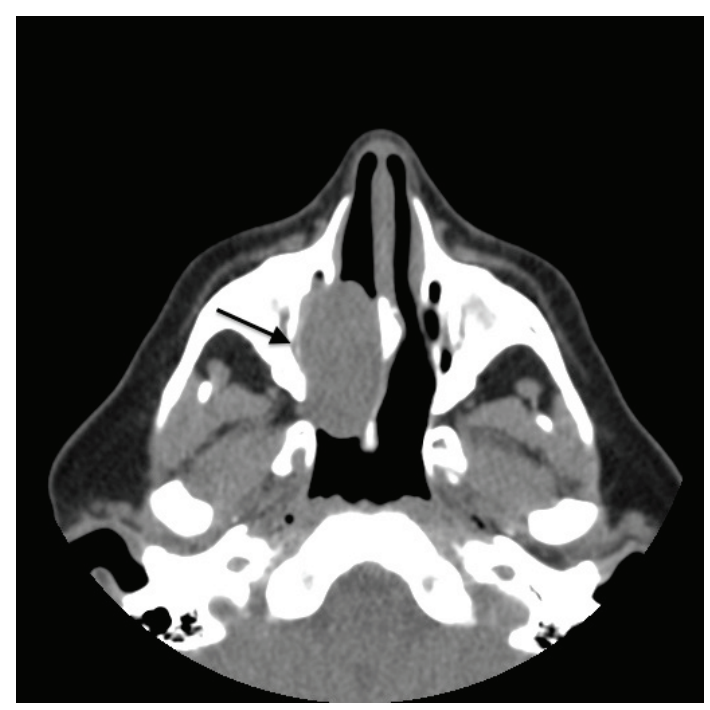

Figure 1. Axial facial CT image demonstrated a $3.4 \mathrm{~cm}$ soft tissue mass in the right nasal cavity (black arrow). 


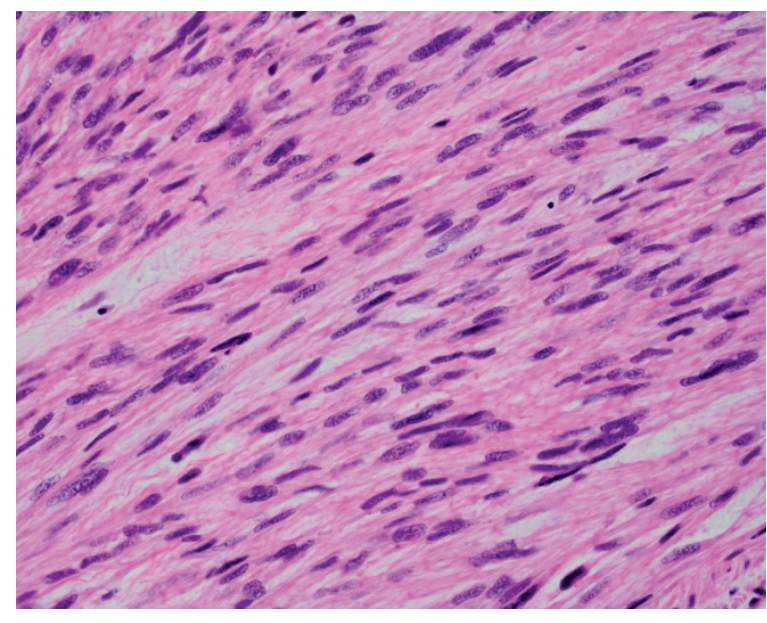

Figure 2. Microscopic examination of the right nasal mass excisional biopsy (hematoxylin and eosin stain; 400x magnification) showing atypical spindle cell neoplasm.

At 32 years of age she presented with a new palpable right breast mass. A $1.6 \mathrm{~cm}$ irregular high density mass with microlobulated and illdefined margins (Figs. 3 and 4 ) in the subareolar region was demonstrated on digital mammography. Targeted right breast ultrasound of the subareolar region at the 11:30 position demonstrated a hypoechoic mass with microlobulated margins measuring $1.4 \mathrm{~cm}$ (Fig. 5), correlating with the mammographic abnormality. The differential diagnosis for the imaging findings included mammary carcinoma, fibroadenoma, and phyllodes tumor. A BIRADS 4 assessment was given and ultrasound-guided biopsy recommended. A second small 10 $\mathrm{mm}$ oval circumscribed isodense mass was also noted on mammogram and ultrasound at the 6:00 position. This mass was determined to be probably benign, a BIRADS 3 assessment given and a 6 month follow-up mammogram was recommended. The patient's physician preferred that both lesions be biopsied.

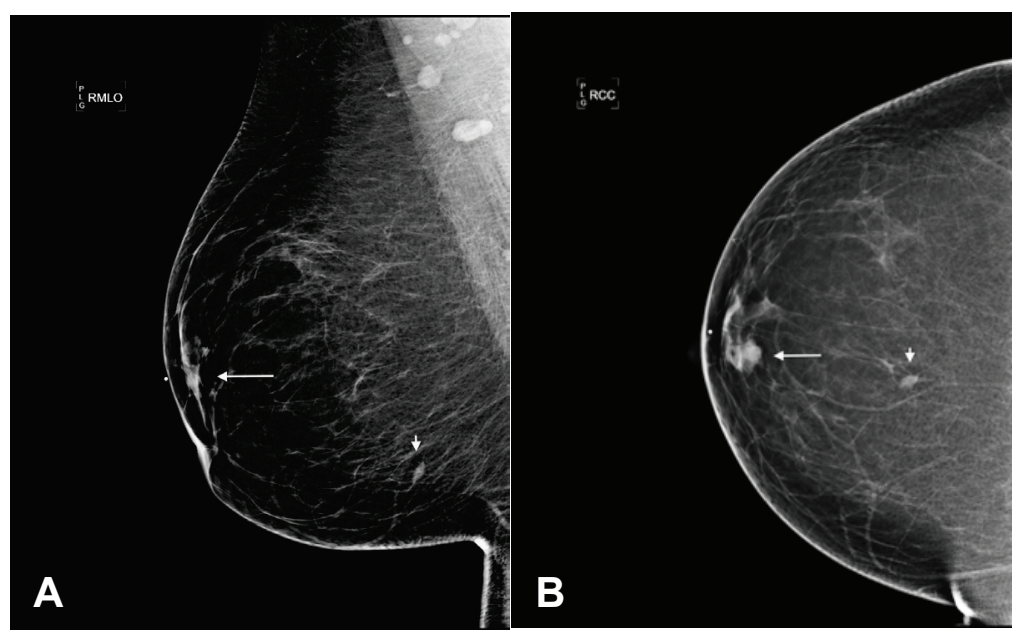

Figure 3. Right CC (A) and MLO (B) views demonstrate a $1.6 \mathrm{~cm}$ irregular subareolar mass (white arrow). A second small $10 \mathrm{~mm}$ oval isodense mass was also noted at the 6:00 position (white arrow head). 


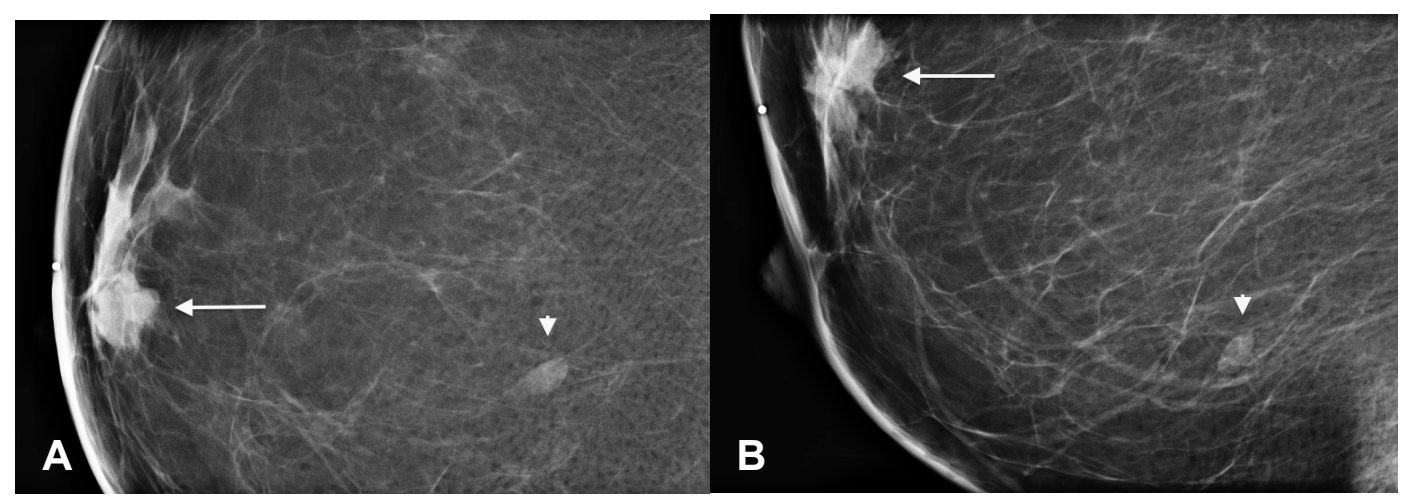

Figure 4. Spot compression right CC (A) and MLO (B) views demonstrate persistence of the irregular subareolar mass with microlobulated and illdefined margins (white arrow). The second small $10 \mathrm{~mm}$ oval isodense mass also persists at the 6:00 position with circumscribed borders (white arrow head).

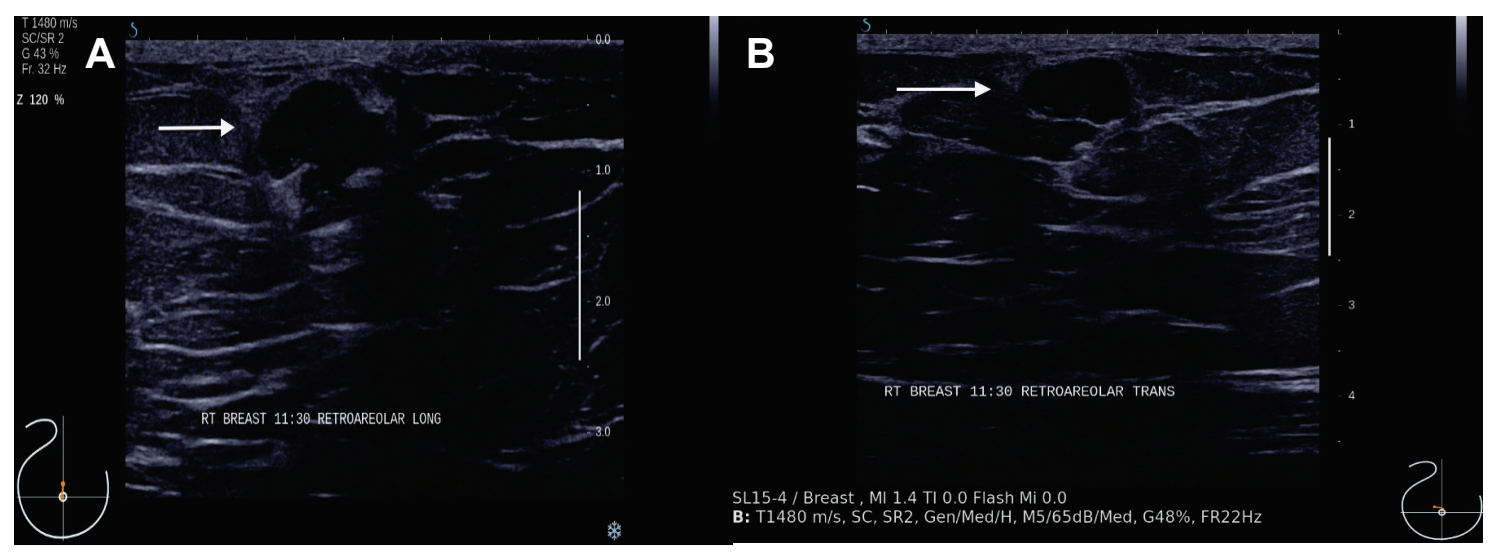

Figure 5: Longitudinal (A) and transverse (B) ultrasound images demonstrate a lobulated hypoechoic mass with microlobulated borders measuring $1.4 \mathrm{~cm}$ (white arrow).

Ultrasound-guided core biopsy of both lesions was subsequently performed. Pathology of the smaller likely benign lesion at the 6:00 position showed fibroadenoma. The core biopsy of the palpable mass demonstrated at least a borderline phyllodes tumor on histopathology, and surgical excision was recommended. The patient returned for surgical excision, with pathology demonstrating malignant phyllodes tumor (Fig. 6). Chromosomal analyses were not reported on any of her tumors. The patient initially underwent lumpectomy with close margin $(1 \mathrm{~mm}$ from anterior inferior resection margin). Central breast excision was performed six weeks later and no residual tumor was identified. At this time, there is no evidence of recurrence of the phyllodes. 


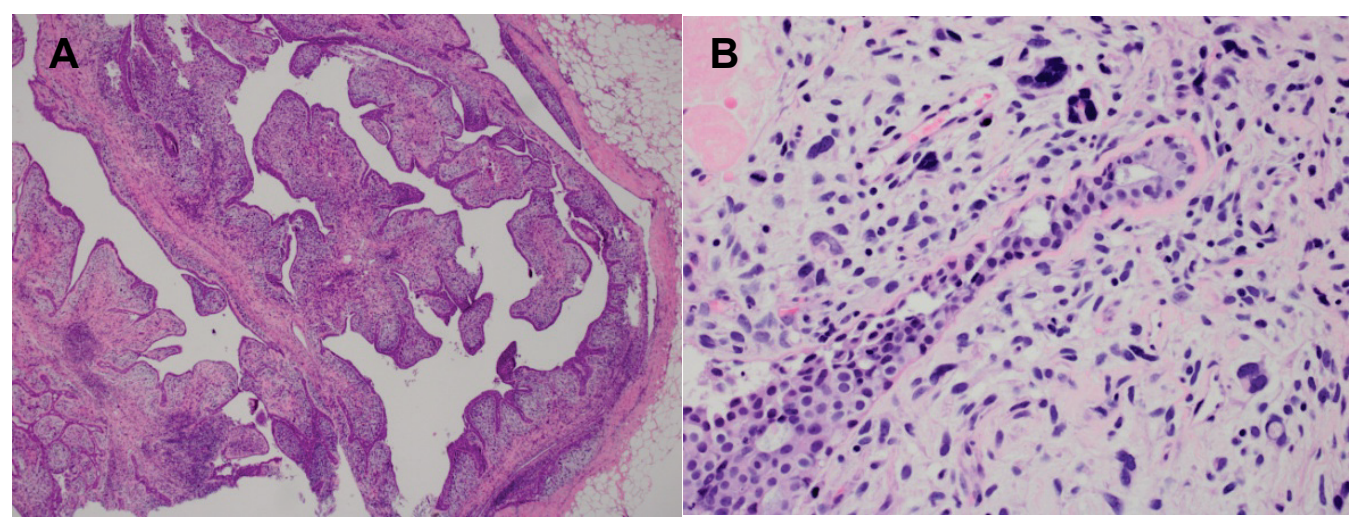

Figure 6: Microscopic examination (hematoxylin and eosin stain) of the palpable breast mass at A) 20x magnification showing a fibroepithelial neoplasm with dilated epithelial lined clefts and B) at 400x magnification with stromal hypercellularity, atypia, and mitoses.

Subsequently, the patient developed a second recurrence of the nasal leiomyosarcoma at the age of 33 . She was treated surgically and is currently receiving external beam radiation therapy.

\section{Discussion}

Phyllodes tumors are uncommon breast tumors that frequently present as rapidly enlarging palpable masses. They average $3-6 \mathrm{~cm}$ in size at presentation, although tumor sizes from $1 \mathrm{~cm}$ to over $20 \mathrm{~cm}$ have been reported. Liberman et al. reported that tumors $3 \mathrm{~cm}$ or greater were significantly more likely to be malignant. ${ }^{13}$ Mammography typically demonstrates a large, round to oval, high density mass with circumscribed and lobulated margins. Sonography usually demonstrates a lobulated, welldefined, heterogeneous, hypoechoic mass without posterior acoustic shadowing. ${ }^{14}$ There may be internal cystic spaces. ${ }^{13}$ Irregular shape has been significantly correlated with malignant and borderline phyllodes tumors. ${ }^{15}$ Color Doppler imaging frequently demonstrates some degree of internal vascularity. In our case, the malignant phyllodes showed irregular shape with microlobulated and ill-defined borders on mammography and hypoechoic mass with microlobulated borders on ultrasound, consistent with the reported imaging findings of malignant phyllodes tumors. On MRI, phyllodes tumors appear round or lobulated with smooth margins and often demonstrate heterogeneous signal intensity with cystic areas and nonenhancing septations. Signal intensity on T2 weighted imaging is variable and nearly always inhomogeneous. T1 signal intensity is usually iso- or hypointense to adjacent breast parenchyma. ${ }^{15}$ Enhancement kinetics are variable. ${ }^{16}$

Phyllodes tumors are treated with wide local excision. Margins of at least $1 \mathrm{~cm}$ are recommended. Local recurrence is reported to occur in 
approximately $3-19 \%$ of patients. Sentinel lymph node biopsy or axillary dissection is not routinely performed, unless clinically indicated. There is no role for adjuvant chemotherapy, radiation therapy or hormonal therapy in the treatment of primary phyllodes tumor. Chemotherapy and radiation therapy may be considered on a case by case basis in the setting of recurrence or metastases. The survival rate of malignant phyllodes is much higher than nonphyllodes breast cancer. There is no data regarding differences in prognosis or management of malignant phyllodes in patients with or without retinoblastoma.

Retinoblastoma occurs in both sporadic (somatic mutation) and familial (germinal mutation) forms. Knudson's "two hit" hypothesis to explain retinoblastoma tumorigenesis requires two complementary chromosomal mutations. ${ }^{17}$ In the familial form of retinoblastoma, the 'first hit" is a germline mutation followed by a somatic mutation of the remaining wild-type copy. These individuals are thus more susceptible to second non-ocular tumors because every cell in the body carries the germline mutation.

The retinoblastoma susceptibility gene $R B 1$, located on the long (q) arm of chromosome 13 at position 14.2, functions as a tumor suppressor gene. The protein encoded by $R B 1$, known as retinoblastoma protein or $\mathrm{pRB}$, is vital to numerous cell processes, including DNA repair, cell cycle control, DNA replication, and proliferation. ${ }^{18}$ Cells with two altered copies of the RB1 gene produce no functional $\mathrm{pRB}$ and are unable to regulate cell division effectively.

It is well known that hereditary retinoblastoma patients are susceptible to a wide variety of second malignancies, particularly soft tissue sarcomas in the setting of prior radiotherapy. ${ }^{3-7} \quad$ Phyllodes tumors of the breast, however, are uncommonly reported as secondary tumors in these patients. ${ }^{12}$ Recent investigation has identified several chromosomal regions where amplifications, gains and losses were present in phyllodes tumors. ${ }^{19}$ In particular, gains of $1 \mathrm{q}$ and losses of $13 q$ are hallmark alterations in borderline and malignant phyllodes tumors. Likewise, losses of $13 q$ are identified in approximately $70 \%$ of leiomyosarcomas. ${ }^{20}$ Similar to phyllodes tumor, gains at $1 \mathrm{q}$ are identified in $50 \%$ of cases of retinoblastoma. ${ }^{21}$ The shared chromosomal alterations in these three tumor types suggest common genetic and cell signaling pathways that are altered and are in need of further study. Clinically, these patients are at high risk for developing a variety of malignancies in multiple sites, and thus close surveillance is necessary.

\section{Conclusion}

Retinoblastoma, malignant phyllodes tumor and nasal leiomyosarcoma are rare tumors. It is unlikely that these tumors would sporadically occur in the same patient. Recent chromosomal analysis suggests a 
possible common genetic etiology of phyllodes tumor and retinoblastoma, particularly 1q gains and $13 q$ losses with RB1 alterations. Further evaluation of the role of RB1 alterations in the oncogenesis of phyllodes tumor is warranted. Furthermore, the differential diagnosis of a breast mass in a patient with a history of retinoblastoma should include phyllodes tumor.

\section{Acknowledgement}

We would like to specially thank for Nichole Jenkins for her help in editing the manuscript.

\section{References}

1. Shields CL, Shields JA. Diagnosis and management of retinoblastoma. Cancer Control. 2004 SepOct;11(5):317-27. PubMed PMID: 15377991.

2. Dryja TP, Mukai S, Petersen R, Rapaport JM, Walton D, Yandell DW. Parental origin of mutations of the retinoblastoma gene. Nature. 1989 Jun 15;339(6225):556-8. PubMed PMID: 2733786. http://dx.doi.org/10.1038/339556a0

3. Kleinerman RA, Tucker MA, Tarone RE, Abramson DH, Seddon JM, Stovall M, Li FP, Fraumeni JF Jr. Risk of new cancers after radiotherapy in long-term survivors of retinoblastoma: an extended follow-up. J Clin Oncol. $2005 \mathrm{Apr}$ 1;23(10):2272-9. PubMed PMID: 15800318.

http://dx.doi.org/10.1200/JCO.2005. $\underline{05.054}$
4. Abramson DH, Frank CM. Second nonocular tumors in survivors of bilateral retinoblastoma: a possible age effect on radiation-related risk. Ophthalmology. 1998 Apr;105(4):573-9; discussion 57980. PubMed PMID: 9544627. http://dx.doi.org/10.1016/S01616420(98)94006-4

5. Woo KI, Harbour JW. Review of 676 second primary tumors in patients with retinoblastoma: association between age at onset and tumor type. Arch Ophthalmol. 2010 Jul;128(7):865-70. doi: 10.1001/archophthalmol.2010.126. PubMed PMID: 20625047.

6. Marees T, Moll AC, Imhof SM, de Boer MR, Ringens PJ, van Leeuwen FE. Risk of second malignancies in survivors of retinoblastoma: more than 40 years of follow-up. J Natl Cancer Inst. 2008 Dec 17;100(24):1771-9. doi: 10.1093/jnci/djn394. Epub 2008 Dec 9. PubMed PMID: 19066271.

7. Wong FL, Boice JD Jr, Abramson $\mathrm{DH}$, Tarone RE, Kleinerman RA, Stovall $M$, Goldman MB, Seddon JM, Tarbell N, Fraumeni JF Jr, Li FP. Cancer incidence after retinoblastoma. Radiation dose and sarcoma risk. JAMA. 1997 Oct 15;278(15):1262-7. PubMed PMID: 9333268.

http://dx.doi.org/10.1001/jama.1997. $\underline{03550150066037}$

8. Lakhani SR, Ellis IO, Schnitt SJ, Tan $\mathrm{PH}$, van de Vijver MJ, editors. World Health Organization Classification of Tumours of the Breast. 4th ed. Lyon: International Agency for Research on Cancer Press; 2012; p. 143-147. 
9. Bernstein L, Deapen D, Ross RK. The descriptive epidemiology of malignant cystosarcoma phyllodes tumors of the breast. Cancer. 1993 May 15;71(10):3020-4. PubMed PMID: 8387873 .

http://dx.doi.org/10.1002/10970142(19930515)71:10<3020::AIDCNCR2820711022>3.0.CO;2-G

10. Vorherr H, Vorherr UF, Kutvirt DM, Key CR. Cystosarcoma phyllodes: epidemiology, pathohistology, pathobiology, diagnosis, therapy, and survival. Arch Gynecol. 1985;236(3):173-81. PubMed PMID: 2990358.

11. Karim RZ, Gerega SK, Yang YH, Spillane A, Carmalt $H$, Scolyer RA, Lee CS. $\quad \mathrm{p} 16$ and $\mathrm{pRb}$ immunohistochemical expression increases with increasing tumour grade in mammary phyllodes tumours. Histopathology. 2010 Jun;56(7):868-75. doi: 10.1111/j.1365-2559.2010.03562.x Epub 2010 May 19. PubMed PMID: 20497245.

12. Mak J. Two cases of malignant phyllodes tumor in patients with history of bilateral retinoblastoma - a possible novel association with RB1 germline mutations. ASHG American Society of Human Genetics Annual Meeting; October 23-27, 2007; San Diego, CA. Available at: http://www.ashg.org/genetics/ashg0 7s/f21566.htm Accessed on January 14, 2013.

13. Liberman L, Bonaccio E, HameleBena D, Abramson AF, Cohen MA, Dershaw DD. Benign and malignant phyllodes tumors: mammographic and sonographic findings. Radiology. 1996 Jan;198(1):121-4. PubMed PMID: 8539362.
14. Buchberger W, Strasser K, Heim K, Müller E, Schröcksnadel $\mathrm{H}$. Phylloides tumor: findings on mammography, sonography, and aspiration cytology in 10 cases. AJR Am J Roentgenol. 1991 Oct;157(4):715-9. PubMed PMID: 1654022.

15. Tan $\mathrm{H}$, Zhang $\mathrm{S}$, Liu $\mathrm{H}$, Peng $\mathrm{W}$, Li R, Gu Y, Wang X, Mao J, Shen X. Imaging findings in phyllodes tumors of the breast. Eur J Radiol. 2012 Jan;81(1):e62-9. doi: 10.1016/j.ejrad.2011.01.085. Epub 2011 Feb 25. PubMed PMID: 21353414.

16. Wurdinger $S$, Herzog $A B$, Fischer DR, Marx C, Raabe G, Schneider A, Kaiser WA. Differentiation of phyllodes breast tumors from fibroadenomas on MRI. AJR Am J Roentgenol. 2005 Nov;185(5):131721. PubMed PMID: 16247156. http://dx.doi.org/10.2214/AJR.04.16 $\underline{20}$

17. Knudson AG Jr. Mutation and cancer: statistical study of retinoblastoma. Proc Natl Acad Sci U S A. 1971 Apr;68(4):820-3. PubMed PMID: 5279523.

18. Classon M, Harlow E. The retinoblastoma tumour suppressor in development and cancer. Nat Rev Cancer. 2002 Dec;2(12):910-7. PubMed PMID: 12459729.

19. Laé $M$, Vincent-Salomon $A$, Savignoni A, Huon I, Fréneaux $P$, Sigal-Zafrani B, Aurias A, SastreGarau X, Couturier J. Phyllodes tumors of the breast segregate in two groups according to genetic criteria. Mod Pathol. 2007 Apr;20(4):435-44. Epub 2007 Mar 2. PubMed PMID: 17334353. http://dx.doi.org/10.1038/modpathol. $\underline{3800756}$ 


\section{Proceedings in Obstetrics and Gynecology, 2013; 3(2):5}

20. Derré J, Lagacé R, Nicolas A, Mairal A, Chibon F, Coindre JM, Terrier $P$, Sastre $X, \quad$ Aurias $A$. Leiomyosarcomas and most malignant fibrous histiocytomas share very similar comparative genomic hybridization imbalances: an analysis of a series of 27 leiomyosarcomas. Lab Invest. 2001 Feb;81(2):211-5. PubMed PMID: 11232643.

http://dx.doi.org/10.1038/labinvest.3 $\underline{780229}$

21. Mairal A, Pinglier E, Gilbert E, Peter $M$, Validire $P$, Desjardins L, Doz F, Aurias A, Couturier J. Detection of chromosome imbalances in retinoblastoma by parallel karyotype and $\mathrm{CGH}$ analyses. Genes Chromosomes Cancer. 2000 Aug;28(4):370-9. PubMed PMID: 10862045.

http://dx.doi.org/10.1002/10982264(200008)28:4<370::AIDGCC2>3.0.CO;2-8 